\title{
Three patients with cor triatriatum sinister detected in adulthood
}

\author{
Ivana Jurin, \\ Josip Vincelj, \\ Diana Rudan, \\ Mario Udovičić, \\ Sandra Jakšić \\ Jurinjak, \\ Jasmina Ćatić, \\ Petra Vitlov*, \\ Tomislava Bodrožić \\ Džakić Poljak
}

University Hospital Dubrava, Zagreb, Croatia

RECEIVED:

March 11, 2017

ACCEPTED:

April 6, 2017

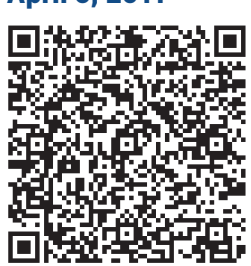

Cardiologia Croatica 2017:12(4):158
KEYWORDS: cor triatriatum, transthoracic echocardiography, transesophageal echocardiography, pulmonary hypertension

CITATION: Cardiol Croat. 2017;12(4):158. | https://doi.org/10.15836/ccar2017.158

*ADDRESS FOR CORRESPONDENCE: Petra Vitlov, Klinička bolnica Dubrava, Avenija Gojka Šuška 6, HR-10000 Zagreb, Croatia. / Phone: +385-91-899-1911 / E-mail: petra.vitlov@gmail.com

ORCID: Ivana Jurin, http://orcid.org/0000-0002-2637-9691 • Josip Vincelj, http://orcid.org/0000-0003-0064-9128 Diana Rudan, http://orcid.org/0000-0001-9473-2517 • Mario Udovičić, http://orcid.org/0000-0001-9912-2179 Sandra Jakšić Jurinjak, http://orcid.org/0000-0002-7349-6137 • Jasmina Ćatić, http://orcid.org/0000-0001-6582-4201 Petra Vitlov, http://orcid.org/0000-0001-6983-1409 • Tomislava Bodrožić Džakić Poljak, http://orcid.org/0000-0002-7293-3972

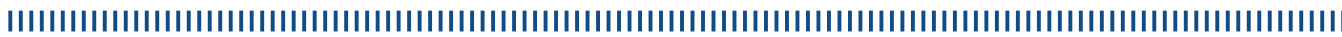

Introduction: Cor triatriatum is one of the rarest congenital cardiac anomalies accounting for 0.1-0$4 \%$ of all congenital heart disease. It is frequently associated with other congenital heart defects and is normally diagnosed in childhood mostly because it is symptomatic with symptoms of left heart obstruction or arrhythmia. ${ }^{1-3}$ We present three cases of cor triatriatum sinister diagnosed in adult age with successful conservative treatment and follow up.

Case report: First patient was a 30 -year-old gravida with an asymptomatic, recently diagnosed cor tratriatum sinister. She has had a history of heart murmur since childhood, but has never been properly evaluated because she had good effort tolerance. Transthoracic (TTE) and transesophageal (TEE) 2D and 3D echocardiogram documented a fibromuscular membrane across the left atrium, dividing it into two compartments, with the proximal one receiving the pulmonary venous flow. Together with the gynecologist we decided to continue with the conservative approach. A healthy baby girl was successfully delivered at 38 weeks' gestation, without any complications. Second patient was a 70-year-old woman that was referred to our emergency unit because of dyspnea and palpitations in the last two weeks, with more frequent episodes in the previous days and nonspecific anterior chest discomfort. TTE showed an abnormal membrane that bisects the left atrium into two chambers, an enlargement of right atrium, a mitral and tricuspid regurgitation and a reduced ejection fraction with pulmonary hypertension. On color Doppler was visualized a left-right (L-D) shunt with two jets. L-D shunt with two jets was confirmed on TEE, one jet on interatrial and membrane conjunction and second in proximal part of interatrial septum. The patient refused operative treatment and was successfully treated with pharmacological therapy. The third case was a 33-year-old men that was referred to TTE because of palpitations and a cor triatriatum without shunt was recognized.

Conclusion: Cor triatriatum is a rare congenital heart disease with varying presentations. The golden standard in three dimensional TTE and TEE.

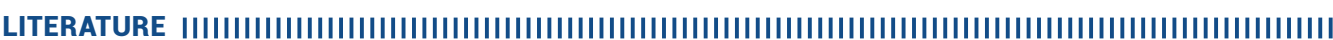

1. Naimo PS, Konstantinov IE. Cor triatriatum sinister: Is it less sinister in older patients? J Thorac Cardiovasc Surg. 2015 Nov;150(5):e77-8. https://doi.org/10.1016/j.jtcvs.2015.08.030

2. Nassar PN, Hamdan RH. Cor Triatriatum Sinistrum: Classification and Imaging Modalities. Eur J Cardiovasc Med. 2011 Jan;1(3):84-87. https://www.ncbi.nlm.nih.gov/pubmed/22379596

3. Bassareo PP, Tumbarello R, Mercuro G. Cor triatriatum and lipomatous hypertrophy of the interatrial septum in the elderly: a case report. Cardiovasc Ultrasound. 2010 Mar 9;8:4. https://doi.org/10.1186/1476-7120-8-4 